\title{
Animales míticos en el mundo clásico
}

\author{
Pilar González Serrano *
}

\begin{abstract}
RESUMEN
No podemos decir que los antiguos griegos practicaran la zoolatría en el sentido estricto de la palabra, su mente analítica y racionalista, contraria al caos

primigéneo, concibió un cosmos ordenado, tras el combate en el que dioses y humanos juntos, combatieron a los gigantes, es decir, contra cualquier cosa brutal y desproporcionada de la naturaleza misma. Y sólo en este sentido, gustaron representar monstruosas criaturas que eran, de hecho los errores de Gea, los errores de la madre tierra.

Por otra parte, el resultado de la fantasía simbólica de los griegos fue una larga serie de monstruos, en la mayoría de los casos de inspiración oriental, que significaron los peligros, sobre todo los peligros del mar y los límites occidentales del Mediterráneo al que los navegantes se tenían que enfrentar, pero lo más interesante es que tanto los animales reales: toros,
\end{abstract}

ABSTRACT

We can't say tha the ancient greeks practised the zoolatrie in the strict sense of the word. Their analytic and rational mind opposite to the primigenious chaos, conceived a methodical «Cosmos», after the fight in which the gods and humans together, combated against the giants; it means, againts everything brutal and desproportionate of the Nature itself. And only in that sense they liked to represent monstruos creatures that were, in fact, the Gea's mistakes, the Mother Earth's mistakes.

On the other hand, the result of the greek's symbolic fantasy was a long series of monsters, in most cases the oriental inspiration that means the dangers, above all the dangers of the sea and the occidental limits of Mediterranean with which the navigators have of face.

But the most interesting thing was both the real animals: bulls, lions,

* Departamento de Arqueología. Universidad Complutense. 
leones, caballos, serpientes, palomas, delfines, etc., como los fantásticos: gorjones, sirenas, sátiros, centauros, etc., fueron transformados por las manos de los artistas griegos en preciosas criaturas para siempre. horses, snakes, doves, dolphins, etc., and the fantastic ones: faucets, gorgons, shrews, sirens, satyrs, centaurs, etc., were transformed by the hands of the greek artists in the beautiful creatures forever.

No puede decirse que los griegos practicasen la zoolatría en el sentido

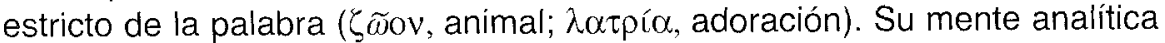
y racionalista, contraria al caos primigenio, concibió un cosmos ordenado tras la lucha al unisono de dioses y hombres contra los gigantes, es decir, contra los generadores de lo desmesurado y lo brutal de las fuerzas desatadas e incontrolables de la propia Naturaleza. Y sólo en este sentido y en otros que más tarde examinaremos, concibieron y representaron seres anguipedos, criaturas híbridas que, por una razón u otra, se consideraban renglones torcidos de Gea, la madre Tierra (figura 1) que, en consecuencia, no habían merecido ni la categoría de dioses ni la de hombres (áv $\theta \rho \omega \pi \mathrm{o})$.

Igualmente, fruto de la fantasía simbólica de los griegos, fueron una serie de entes monstruosos, muchos de ellos de origen oriental, a través de los cuales se significaron peligros y asechanzas para los hombres tanto

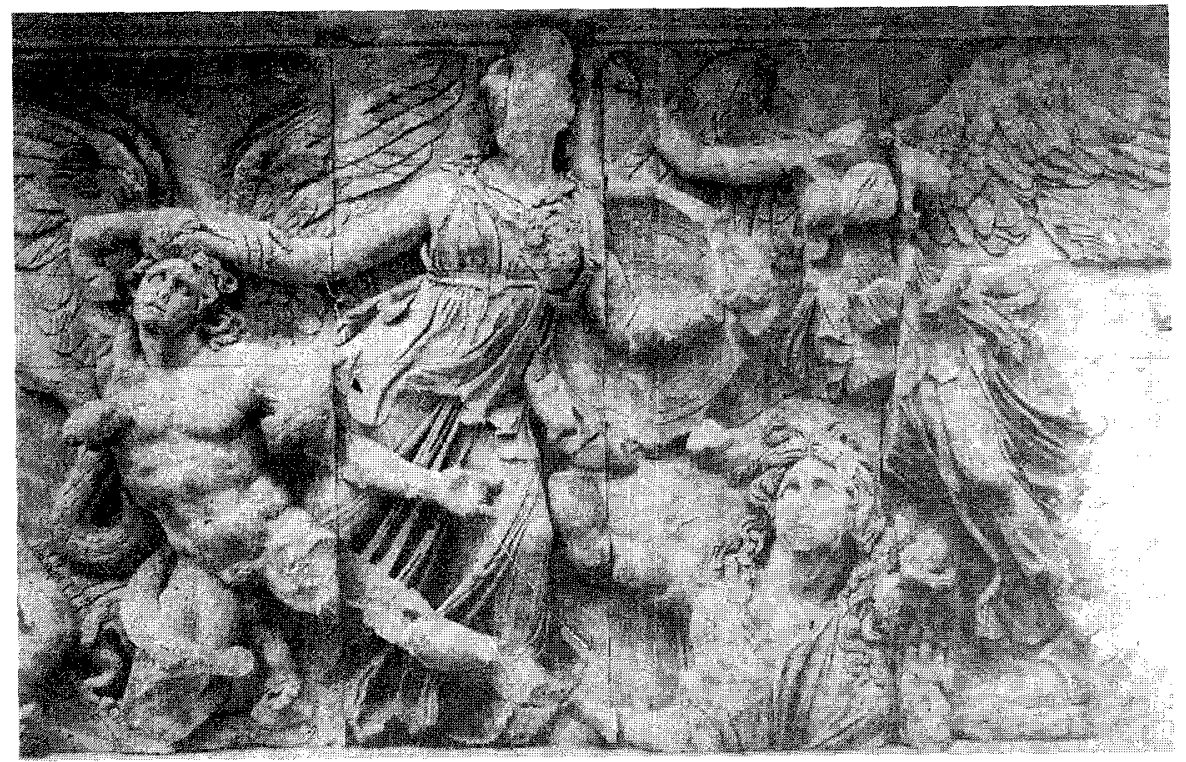

Figura 1. Relieve del Altar de Pérgamo (197-159 a.C.). Lucha de Atenea contra los gigantes ante la suplicante actitud de Gea (ángulo derecho). Museo de Berlín. 


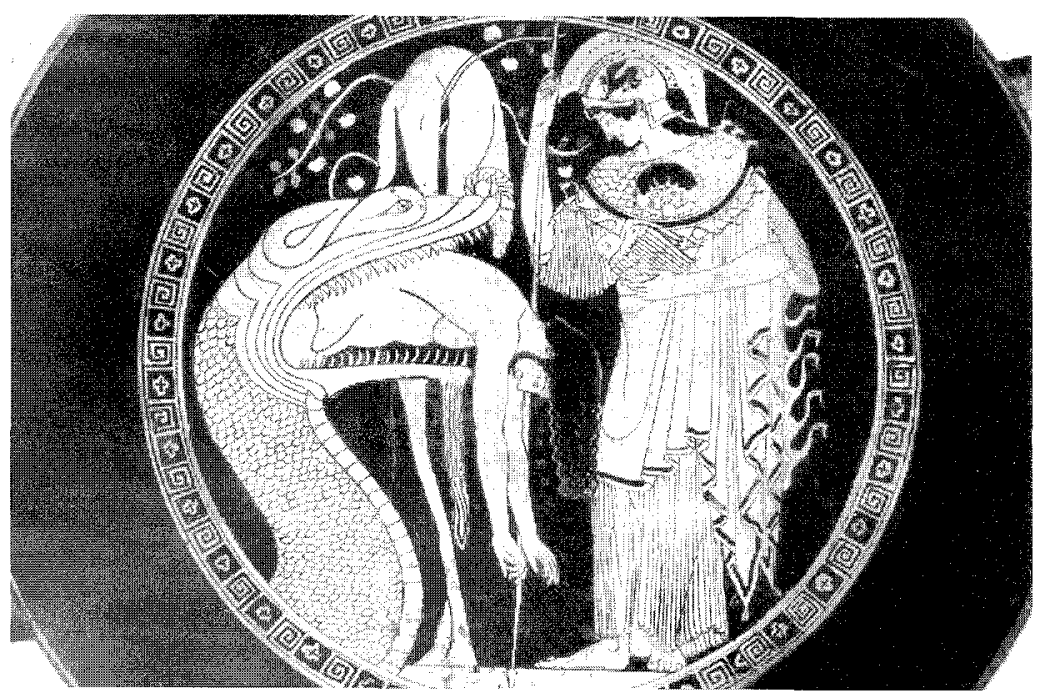

Figura 2. Fondo de un kylix ático de figuras rojas en el que aparece Jasón devorado por el dragón ante la figura de Atenea (480-470 a.C.). Museo Vaticano.

en el mar, el vinoso ponto, como en los desfiladeros y pasos inaccesibles de las montañas y en los lejanos confines de un Occidente mal conocido y siempre envuelto en las brumas de la duda y de los miedos (figura 2). Sin embargo, lo curioso es que hasta estos seres monstruosos, mitad hombres y mitad animales, en las manos de los artistas griegos, se convirtieron en criaturas hermosas y fascinantes. El culto a la belleza como consecución de la suprema armonía, estuvo tan profundamente arraigado en el gusto estético griego, que los artistas (entonces simples obreros especializados, $\tau \varepsilon \chi \nu i ́ \tau \varepsilon s)$ fueron incapaces de cultivar el feísmo, como más tarde harían los etruscos y romanos. La pujanza vitalista de las culturas italianas e hispanas puso y siguen poniendo, en el marco del Mediterráneo, acentos de un intencionado sarcasmo y de un esperpéntico surrealismo, inimaginable en territorios helenos. Valgan como ejemplo las espectaculares y efímeras creaciones de nuestras actuales fallas, fruto de la capacidad creadora, expresionista y desarticulada, de unas formas y volúmenes que son perfectamente entendidas y valoradas por los levantinos, porque sólo a través de ellas, la crítica de la realidad alcanza sus propósitos.

Como muestra de la capacidad idealizante de los helenos frente al realismo itálico, puede servir la comparación entre la Medusa Rondanini (Gliptoteca de Munich), atribuida a Cresilas (figura 3), un escultor de fines del siglo $V$ a.C., y la Medusa que sirvió de antefija en el templo de Veyes, en Etruria, fechable en el siglo VI a.C. (figura 4). La primera respira belleza y 


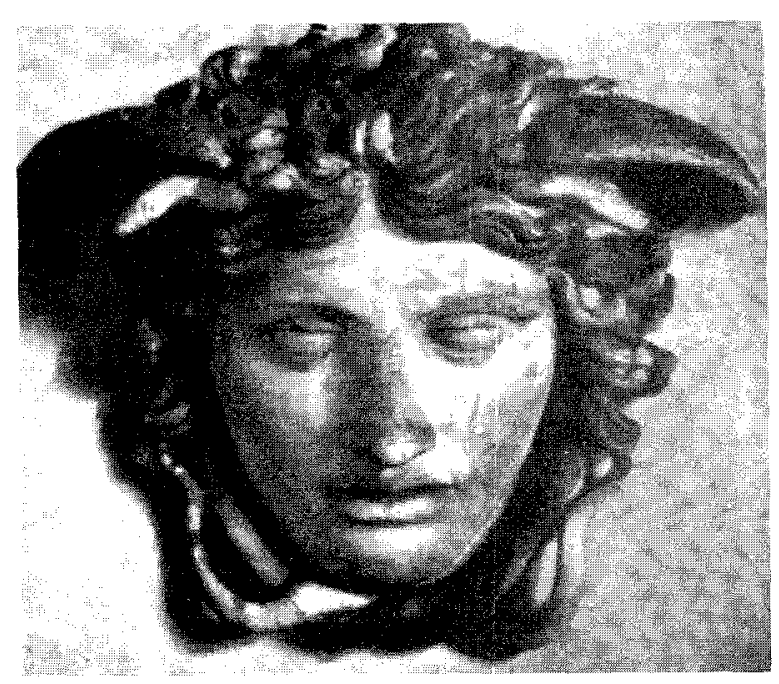

Figura 3. Cabeza de la "Medusa Rondanini» atribuida al escultor Cresilas (fines del siglo V a.C.). Museo de Munich.

serenidad, hasta el punto de que contemplándola resulta difícil imaginar su fascinante crueldad. En la segunda, de época cronológicamente anterior y, por lo tanto, con rasgos arcaizantes, destaca su aspecto caricaturesco y vivaz, casi de ninot de feria, con el que su autor acertó a subrayar su monstruosa y terrorífica condición, de acuerdo con el fin programado.

Por otro lado, hay que tener en cuenta que la capacidad reflexiva del hombre griego, analista meticuloso de sus sensaciones y pasiones, le llevó a acuñar un mito para cada una de ellas, es decir, una síntesis metafórica de toda una serie de pensamientos, magistralmente condensados y mezclados con una fantasía simbólica, única en su género. Por esta razón, los mitos griegos han sido válidos a través del tiempo y aún son claves de comunicación paradigmática a las que recurrimos todos los que aprendimos su lenguaje. Así, por ejemplo, el amor, Eros, a tenor de sus desatinadas y dolorosas jugarretas, se materializó en un mito del que se hizo protagonista, primero a un bello y lánguido adolescente alado, con arco y flechas en sus manos, un ser en plena pubertad por ser la etapa de la vida en la que los efectos del amor se dejan sentir con más fuerza ${ }^{1}$; y más tarde, ya en época

Este Eros se identifica con la representación iconográfica del llamado Amor de Tespis, atribuido a Praxiteles, ya que fue un regalo del escultor a su amante Friné, quién lo donó a su ciudad natal, Tespis. Las copias romanas más famosas del original griego se encuentran en el Museo Vaticano y en el Museo de Nápoles. 


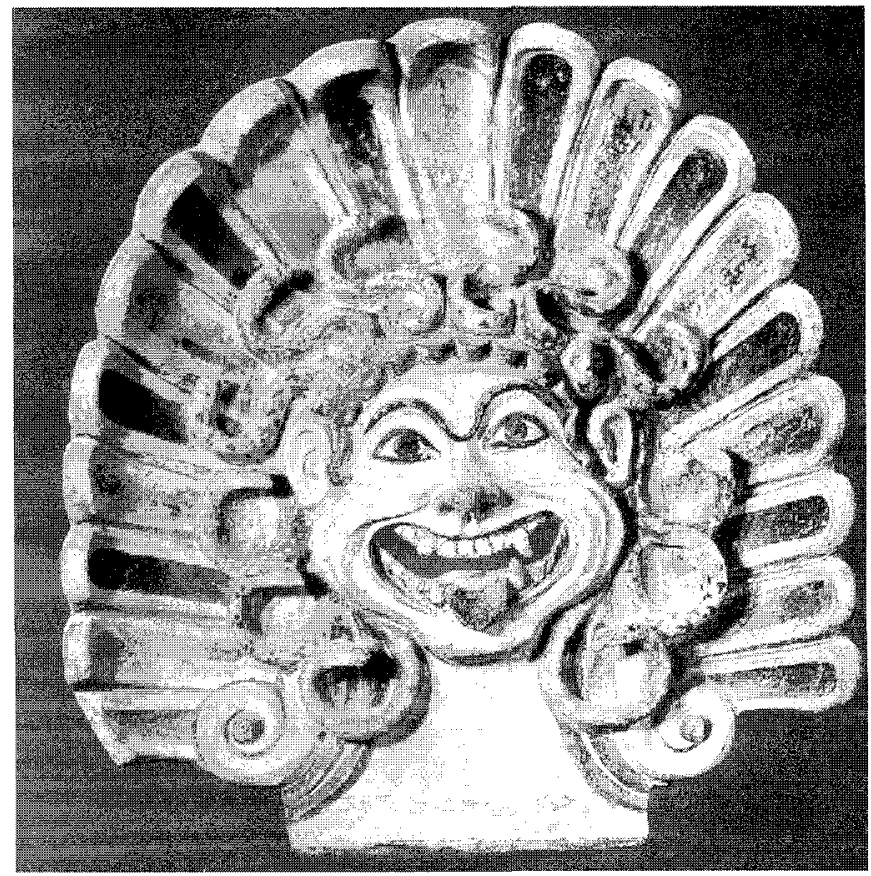

Figura 4. Antefija de terracota policroma del templo de Veyes (Etruria), con la representación de una cabeza de Gorgona (hacia el 500 a.C.). Museo de la Villa Giulia, Roma.

helenística, a un travieso niño, es decir, a un ser irracional, igualmente provisto de un arco y de flechas, que disparaba a su capricho, hiriendo a sus víctimas sin compasión. Como señal de fidelidad y constancia, solía dormirse apaciblemente en los hogares de los amantes felices, pero, llegado el hastío, no dudaba en agitar sus menudas alas amenazando con un súbito vuelo hacia nuevos escenarios ${ }^{2}$. Que el amor es insensato, hace sufrir y puede ser efímero es, evidentemente, algo que todos hemos experimentado en alguna ocasión. Sin embargo, nadie ha sintetizado mejor que los helenos el profundo alcance de este sentimiento universal en una sola imagen.

Todas estas peculiaridades de la cultura griega determinaron la concepción de dioses de aspecto antropomorfo, con una apariencia, por supuesto, más bella y majestuosa que la de los hombres, y poseedores de dotes ex-

2 Esta modalidad de Eros-Cupido se materializó en graciosas estatuillas de infantes regordetes alados, los llamados erotes, que bien durmientes o en actitudes juguetonas, fueron protagonistas de numerosas escenas escultóricas y pictóricas de época helenística y romana. 
traordinarias. De entre ellas destacaban el sumo poder y la inmortalidad porque, sin dioses poderosos e inmortales, los hombres se hubieran quedado sin puntos de referencia. Además, dioses y hombres se necesitaban para mantener el orden establecido, ya que juntos habían vencido a los gigantes. En cambio, las pasiones y necesidades eran semejantes en unos y otros, porque sólo así podía establecerse un recíproco entendimiento.

Por todo esto, no es de extrañar que los griegos, a la hora de manifestarse artísticamente desde mediados del siglo VII a.C., en el llamado período orientalizante, se cansaran pronto de repetir la serie de animales pasantes: grifos, esfinges, sirenas, etc., cuyos repertorios les llegaban desde el Oriente próximo, y que desde el siglo vı a.C., buscaran su inspiración, principalmente, en los episodios de las dos conocidas gestas de época micénica, la llíada y Odisea, difundidas por aedos y rapsodas, en la cuenca mediterránea, a partir del siglo vil a.C., en el período del llamado despertar marinero. $Y$ en estas aventuras de héroes y dioses, aunque existan pasajes en los que sus protagonistas aparezcan bajo el aspecto de un animal o de un monstruo, lo que se exalta, sobre todo, es el triunfo del hombre sobre la fuerza de los cíclopes y los bárbaros tiranos, venciendo al miedo por medio de la inteligencia.

En realidad, como atinadamente señaló Kasantsakis, hijo de una cretense y un oriental, el mirar de frente a los dioses, encarándose con ellos, fue un desafío y una conquista que se fraguó en la isla de Creta, porque en ella, los que jugaron con el toro, saltando entre sus cuernos, perdieron el miedo a la muerte y propiciaron la hazaña de Teseo, es decir, la muerte del Minotauro (figura 5), encarnación del poder absoluto y totalitario, al que había que obedecer ciegamente. A partir de tan célebre tauroctonía se iniciaron tiempos nuevos, tiempos de libertad frente a todos y frente a todo, aunque nadie confesara que en el Laberinto no habia oscuros y ensangrentados corredores y que el monstruo, mitad toro, mitad hombre, no había existido jamás. Tal vez ese fuera el secreto de Ariadna y tal vez por ello Teseo la abandonase en Naxos. Las hipótesis sugerentes acerca de los mitos pueden ser infinitas... $Y$ en esa posibilidad, precisamente, radica su actualidad y grandeza.

\section{ANIMALES REALES Y FANTÁSTICOS EN LAS CIVILIZACIONES PREHELÉNICAS}

No es cuestión de analizar aquí las principales características de las llamadas culturas prehelénicas, pero al menos hay que recordar que la civilización minoica, emparentada con las anatólicas del $v 1$ y $\vee$ milenio a.C., de carácter agrario y ganadero, tuvo como animales sagrados a la sierpe (figura 6 ), en su calidad de ser ctónico, nacido de las entrañas de la tierra; al toro, 


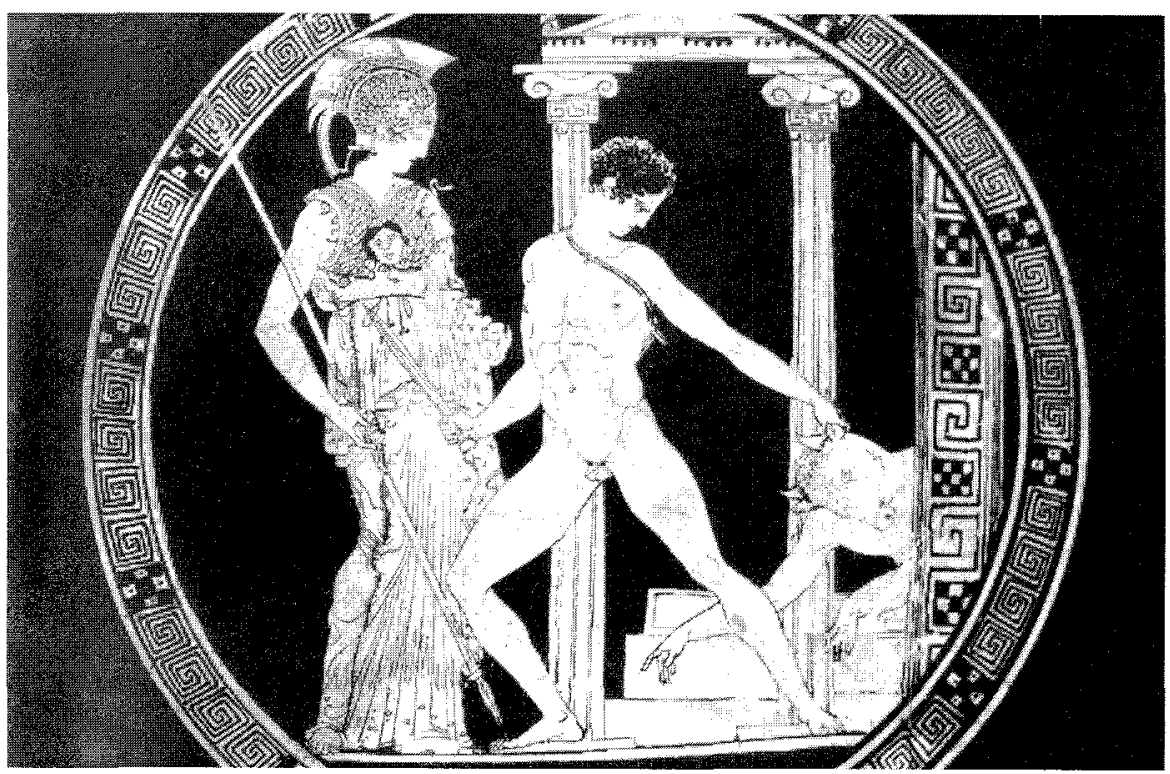

Figura 5. Fondo de un kylix firmado por Aisón (hacia 420 a.C.) en el que figura la representación de la victoria de Teseo sobre el Minotauro, con la presencia de Atenea. Museo Arqueológico Nacional de Madrid.

símbolo del poder genésico y telúrico; y a la paloma (o a un pájaro semejante), «el sacro ucello» de los italianos, que solía aparecer como anuncio de las epifanías o apariciones de los dioses (figura 7). Con estos animales simbólicos y el árbol sagrado, el «albero sacro» que, al igual que el dios joven y fecundante de la madre tierra, renacía y moría cada año, se estableció el ciclo litúrgico y festivo de las religiones egeo-mediterráneas y cretenses, en cuyas principales celebraciones se jugaba con el toro, en un desafío de vida y muerte, para sacrificarle después y consumir su carne como un preciado bocado, no habitual en la dieta cotidiana.

Animales sagrados, como nutricios del gran dios Zeus, criado en la isla de Creta, fueron la cabra Amaltea y la abeja Melissa (figura 8), gracias a las cuales pudo crecer el divino niño y podían ser alimentados otros recién nacidos a los que, por una razón u otra, les faltaba la leche materna.

Los delfines fueron los animales del mar con los que los primitivos mediterráneos se sintieron más familiarizados (figura 9), por ser sus compañeros en las travesías marítimas. Además, su retinas se impregnaron con las imágenes de los cefalópodos de rizados tentáculos, de los corales y caracolas, de las especies marinas propias del mar conocido, la mayoría 


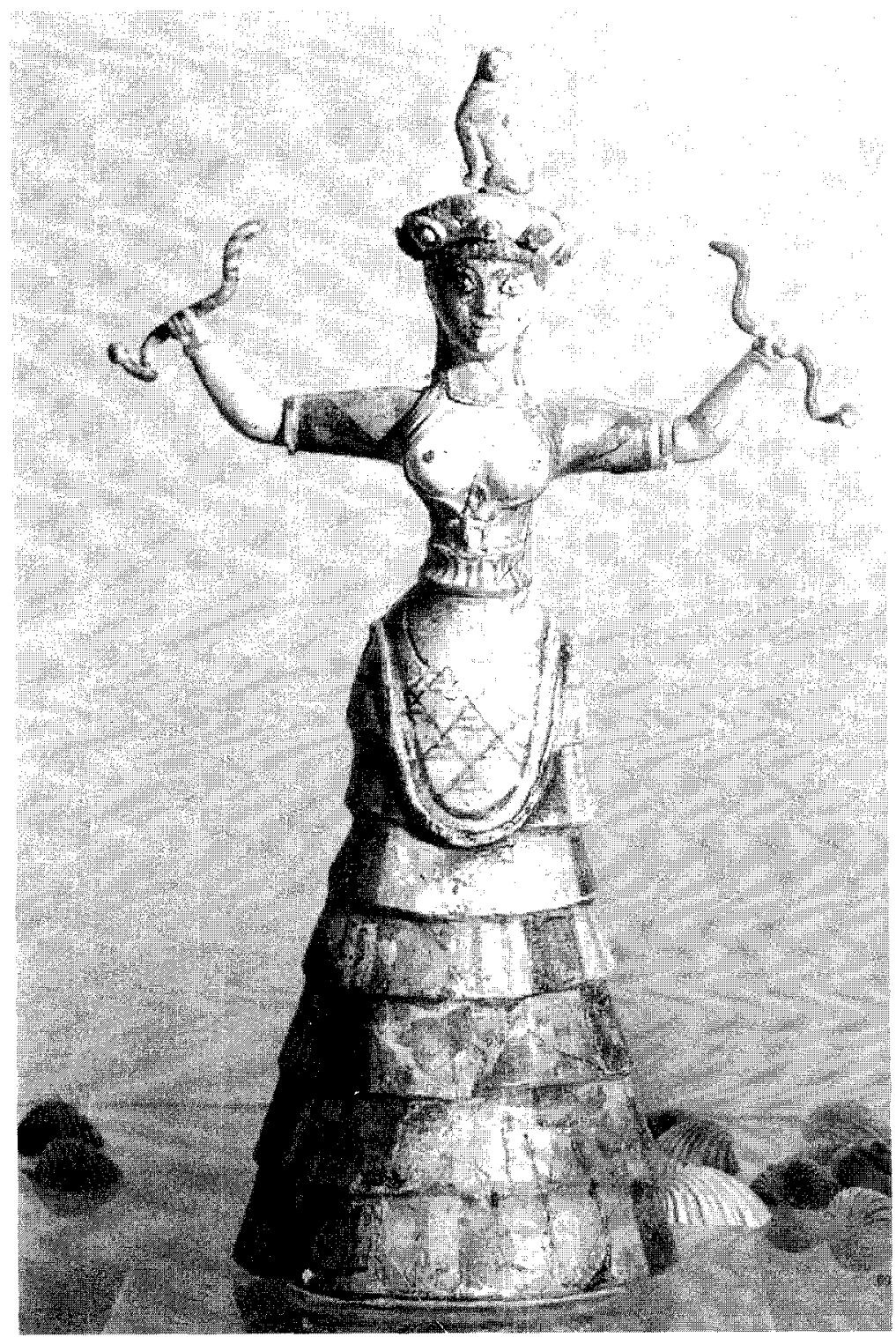

Figura 6. Diosa de las serpientes hallada en el santuario del palacio de Cnoso (Creta). Altura 29,5 cm. (Hacia 1600 a.C.). Museo de Iráklion. 


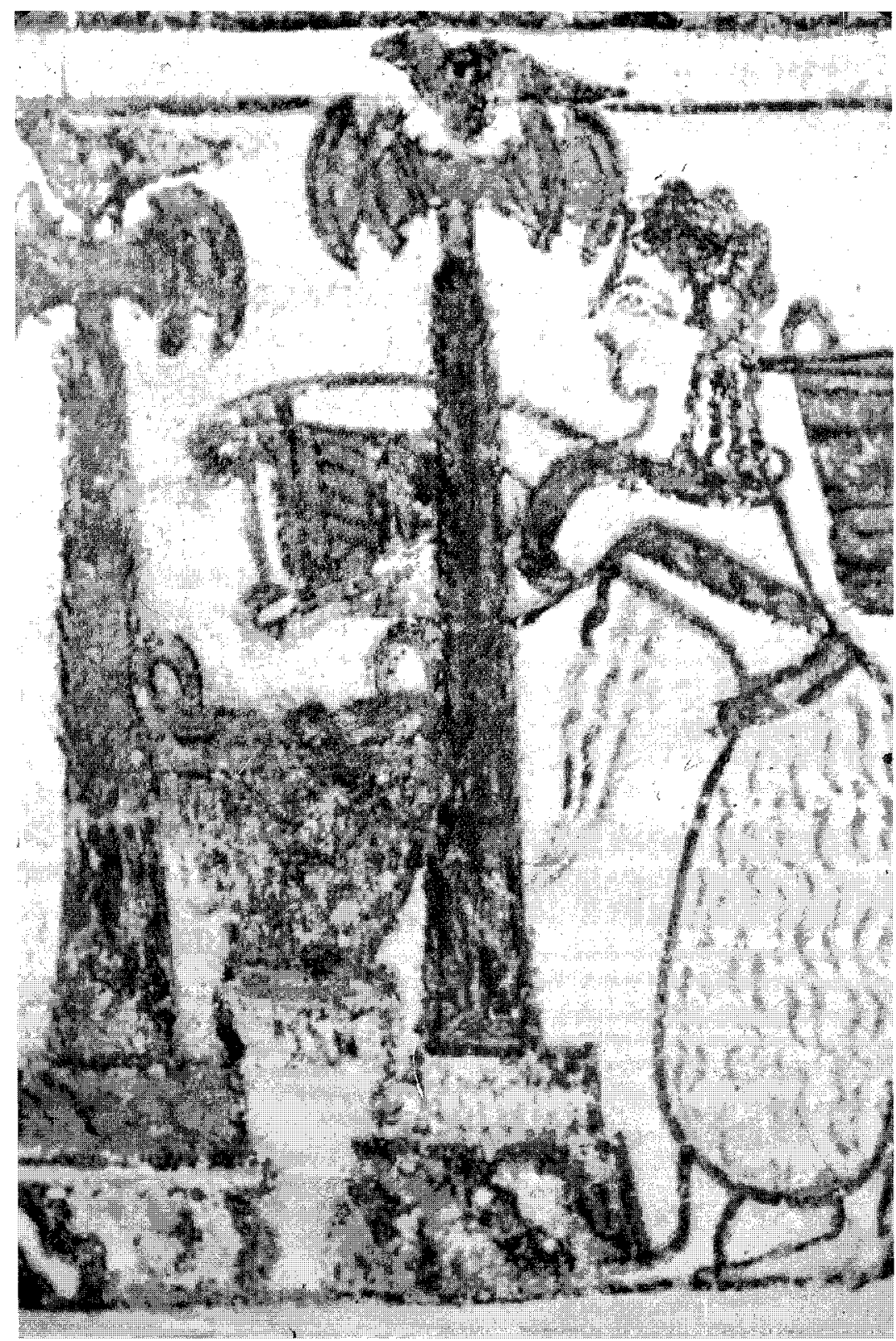

Figura 7. Detalle del sarcófago de Hagía Triada (Creta) en el que aparecen las figuras de dos pájaros posados sobre las «dobles hachas» que enmarcan la crátera de libación (siglo XIV a.C.). Museo de Iráklion. 


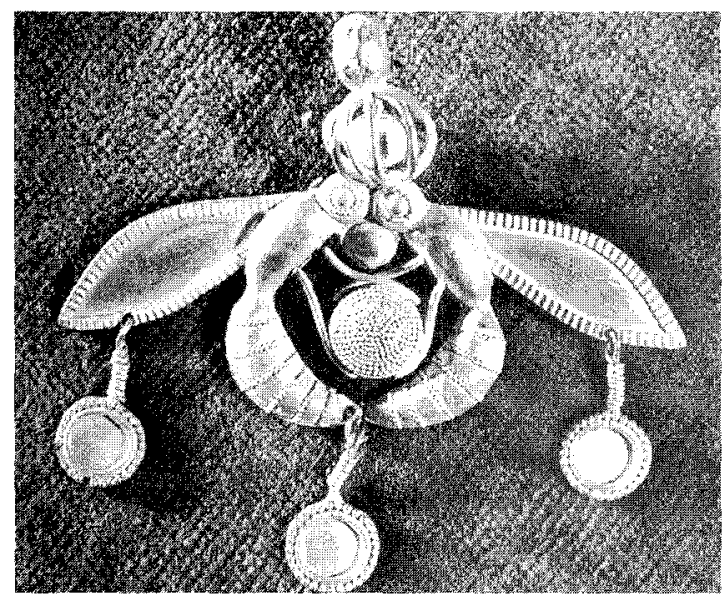

Figura 8. Colgante de oro con dos abejas que sostienen un panal entre sus patas, procedente de la necrópolis de Crisolako, en Malia (Creta). Longitud 4,7 cm. (Hacia 1800 a.C.). Museo Iráklion.

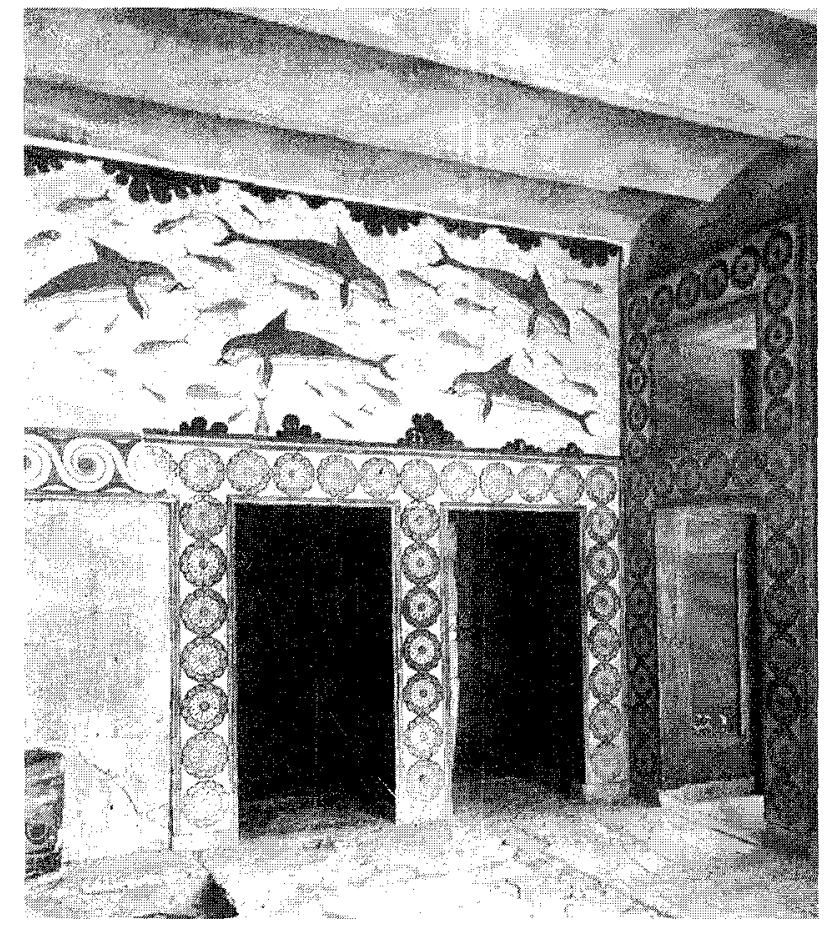

Figura 9. Megarón de la reina en el palacio de Cnoso (Creta) decorado con un panel de estuco policromo en el que aparecen delfines y rocallas marinas (hacia 1500 a.C.) 


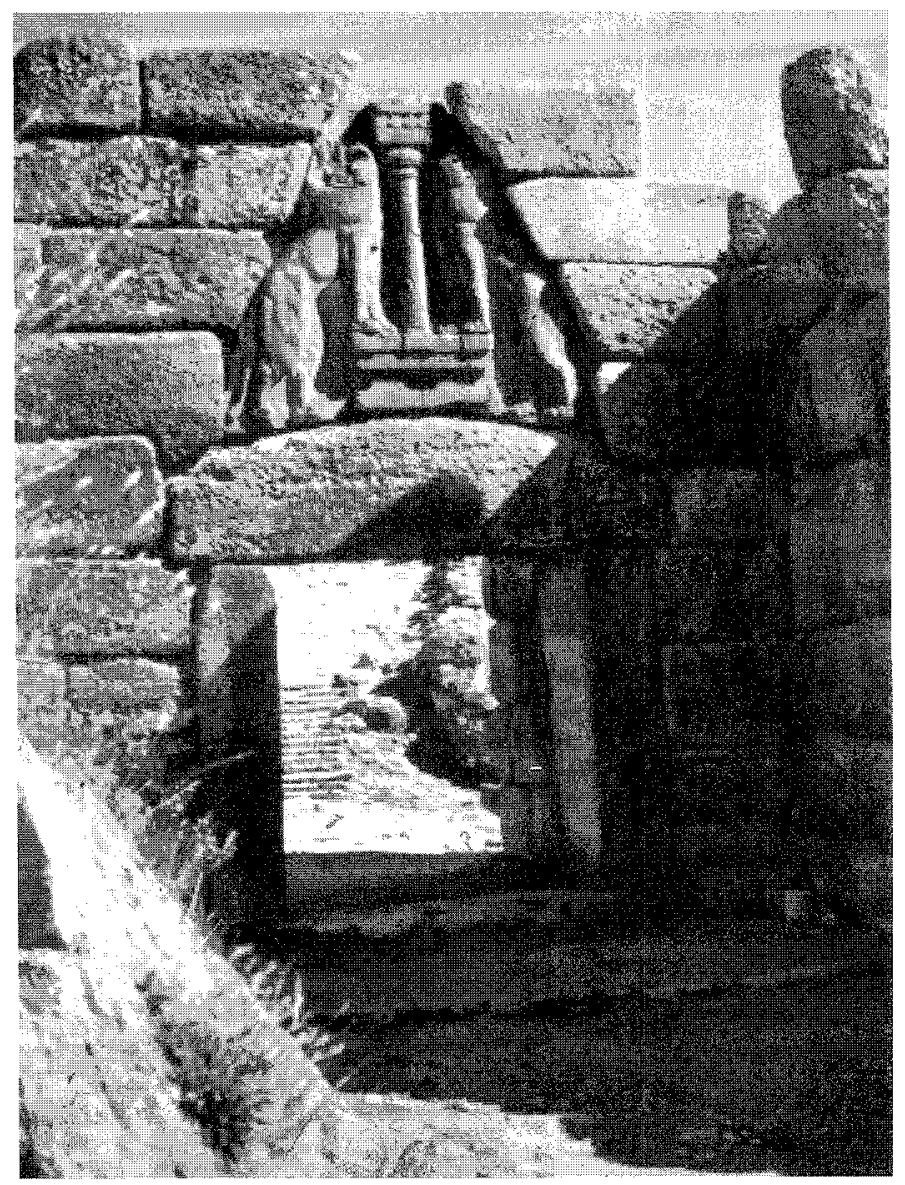

Figura 10. Puerta de los leones de Micenas. En el triángulo de descarga se yerguen dos leones flanqueando una columna (hacia 1250 a.C.).

de las cuales se representaron con todo colorido y vivacidad, tanto en los frescos que decoraron las estancias de los célebres palacios cretenses, como en sus polícromas cerámicas

Aportación de los aqueos, gentes indoeuropeas, que establecidas en Grecia desde el 2000 a.C., se impusieron sobre los cretenses hacía 1400 a.C., fue la exaltación del león, símbolo de la realeza. Mayestáticos son los dos fibrosos felinos que flanquean la columna, cratofanía de la diosa madre, en el gran triángulo de descarga de la monumental Puerta de los Leones de Micenas (figura 10), la casa de los Atridas, como animales no sólo apotropáicos, sino también amenazantes, fieles guardianes de la 
casa de sus poderosos señores. Los aqueos, como viejos pueblos errantes, antes de asentarse en sus posteriores establecimientos, también mantuvieron un especial culto al caballo, un caballo que, con el tiempo, se convirtió en barco, es decir, en un caballo de mar. $Y$ así, el dios de los caballos, Posidón, se transformó en la divinidad marina por excelencia. En un caballo de madera, gigantesco, entraron los griegos en Troya y tomaron la ciudad, lo que demuestra la valoración de dicho animal (figura 11) y la fuerza de su dios patronímico que, tal vez, haciendo uso de su nuevo poder en sus nuevos dominios, lo que hizo fue provocar un maremoto capaz de abrir brechas en las murallas de llión.

Los corceles alados, como seres psicopompos, es decir, conductores de las almas al más allá, aparecen también en algunas ocasiones, por ejemplo en uno de los laterales del Sarcófago de Hagia Triada, mientras que en el otro, el carro del difunto es tirado por dos caballos normales. Con este doble lengua-

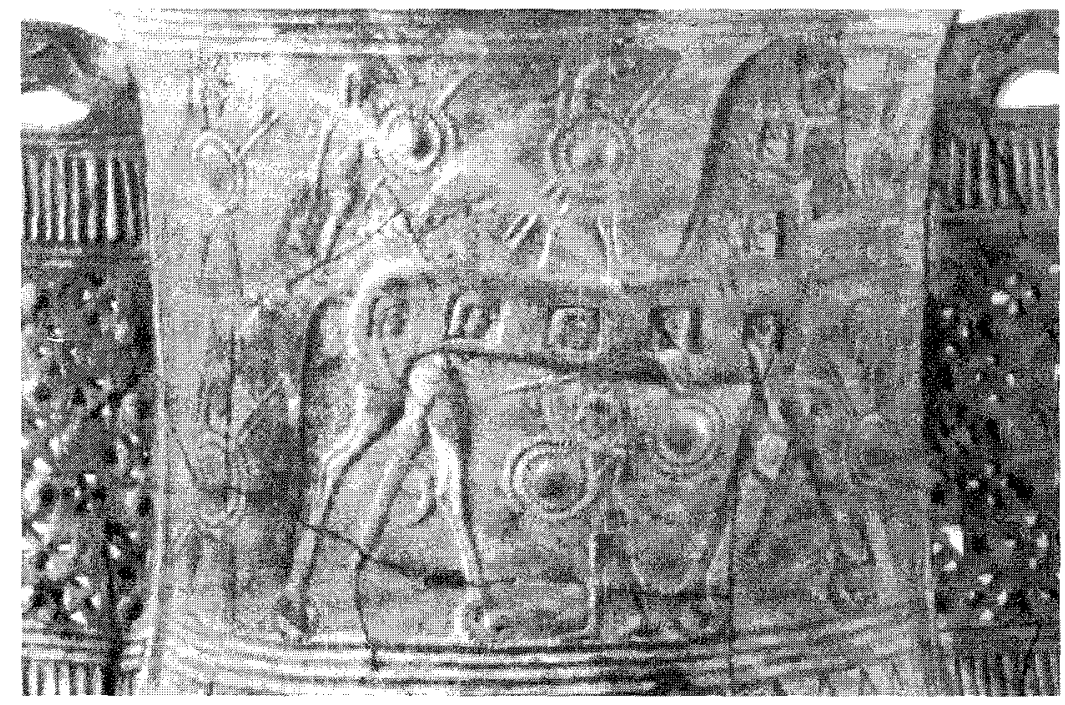

Figura 11. Representación del "caballo de Troya" en un vaso griego (670-650 a.C.). Museo de Mykonos.

je se aludía, por un lado, al plano de la realidad, es decir a la conducción del difunto hasta su última morada y, por otro, al acceso al mundo de ultratumba.

Símbolo de la realeza, pero también en niveles superiores relacionados con el más allá, fue el grifo cresteado, una magnífica creación, llena de fuerza, ya que es una mezcla de los dos animales más poderosos de la naturaleza, el águila que surca los cielos y el león que domina la selva. 


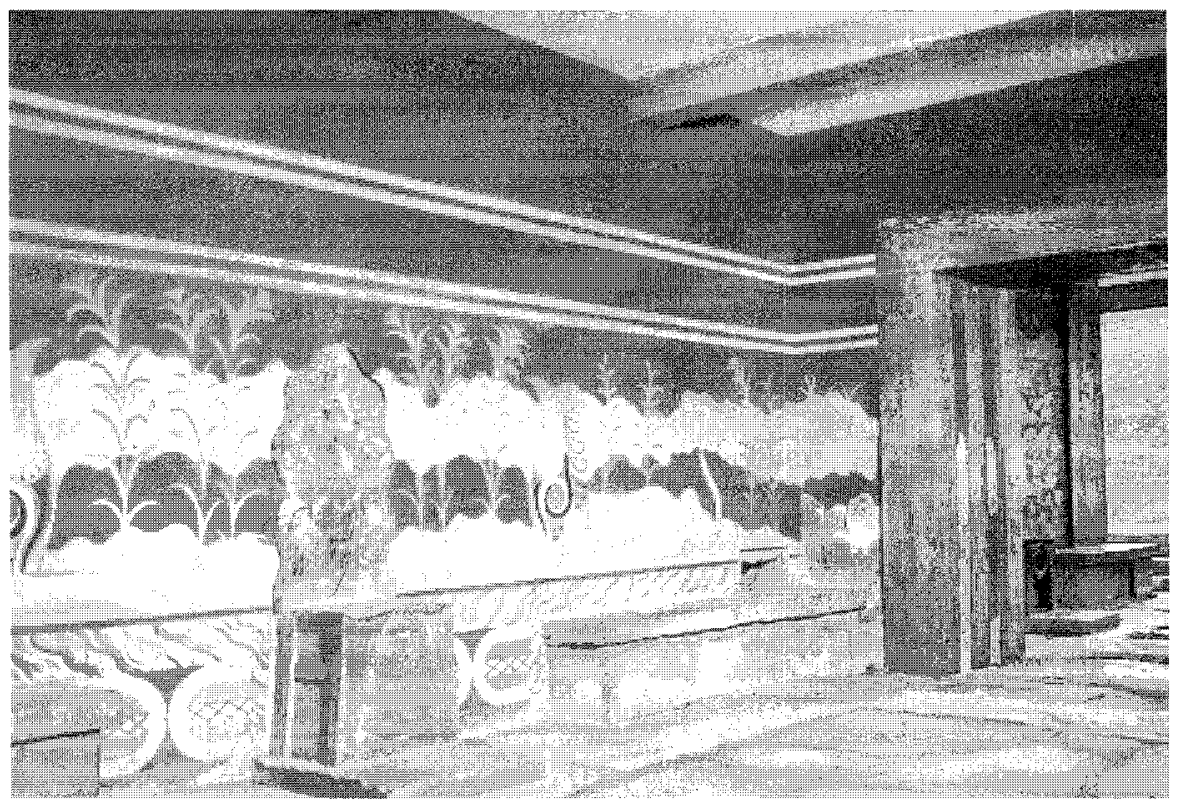

Figura 12. Decoración del Salon del Trono del Palacio de Cnoso (Creta) con dos grifos cresteados (hacia 1400 a.C.).

Luce siempre, como enseña de casta, una potente ceja que enmarca uno de sus ojos y se enrolla sobre uno de sus flancos (figura 12). Dos bellos grifos polícromos flanquean el asiento real del llamado Salón del Trono de Cnoso, cuya decoración es probable que sea de la época en que los aqueos eran ya los señores del palacio, y hermosos grifos aparecen también en muchos de los sellos y chatones micénicos.

Después del 1200 a.C., con la caída de las fortalezas micénicas, como consecuencia del ataque de los llamados pueblos del mar, se inició la Edad Oscura de Grecia, y desde el punto de vista de la plástica, se atravesó por una etapa en la que prevalecieron los repertorios dominados por las formas geométricas primero y las sagas de animales fantásticos, después, de corte orientalizante y con un simple valor ornamental, de todo lo cual se cansaron pronto los griegos, como ya hemos dicho, por lo que comenzaron a aflorar sus relatos de aventuras y peripecias ilustrándolas con imágenes pictóricas que nos han llegado, sobre todo, a través de las pinturas de sus bellos vasos cerámicos. En los primeros tiempos fueron los cíclopes, las gorgonas y las sirenas los heraldos de los peligros del mar, pero pronto, los episodios de los grandes ciclos míticos, en especial del troyano, coparon la actualidad de aquellos momentos y su eco aún perdura entre nosotros. 


\section{ANIMALES REALES CONSIDERADOS MÍTICOS EN EL MUNDO CLÁSICO}

En el mundo de los dioses olímpicos hay que empezar por señalar al águila (figura 13), el ave reina de los cielos, como emblema de Júpiter, y a la lechuza (figura 14) como acompañante de Atenea, la diosa de ojos glau$\cos (\gamma \lambda \alpha u \xi \xi$, lechuza; $\gamma \lambda \alpha v \kappa o ́ \mu \mu \alpha \tau o \zeta$, de ojos azules) de forma que estos dos animales se han convertido en símbolo emblemático de los dos dioses más poderosos del Olimpo y aún gozan de una especial veneración en toda Grecia.

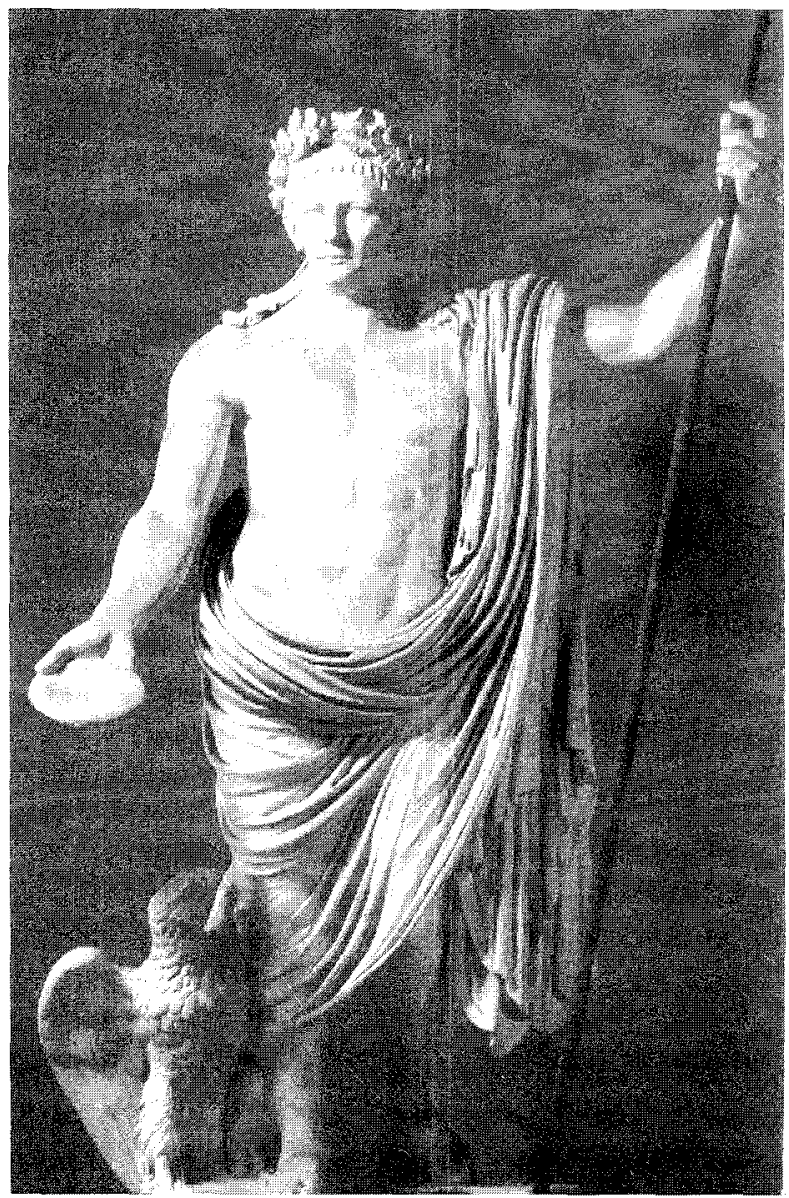

Figura 13. El emperador Claudio (41-54 d.C.) representado como Júpiter, con el águila emblemática a sus pies. Museo Pio Clementino. Vaticano. 


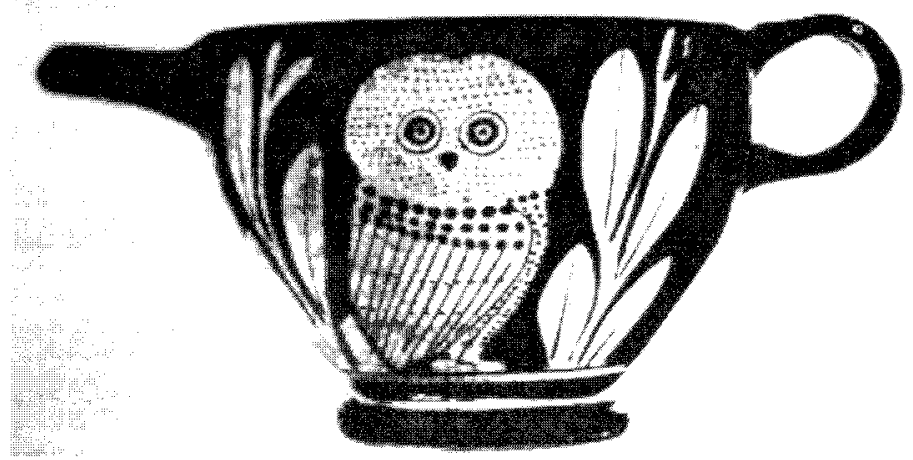

Figura 14. Skyphos ático con la representación de la lechuza de Atenea (siglo v/ a.C.).

Compañeros de Ártemis fueron los corzos y otros astados, así como sus adiestrados perros de caza. En general, fue ella la que heredó muchos

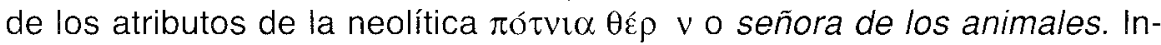
cluso, como recuerdo de un antiquisimo culto al oso, posiblemente de raíces paleolíticas, existieron santuarios en honor de Ártemis Brauronia. El más famoso de todos fue el de Brauron, una de las más antiguas localidades del Ática, donde la diosa recibía culto desde el Heládico medio, y donde se celebraba una ceremonia de iniciación al matrimonio en la que participaban las adolescentes de Atenas. Según la tradición, dicho santuario se levantó para apaciguar la ira de Ártemis porque los habitantes de la región habian matado a unos osos de la diosa que, a su vez, habían despedazado a una muchacha del lugar. Ártemis envió la peste e hizo saber por un oráculo que exigiría que todos los años se le consagrasen las hijas núbiles de las aldeas próximas. Las fiestas de Brauronia tenían lugar cada cinco años, en primavera. Participaban las osas (ळ̋ las niñas disfrazadas de oseznas, en un ambiente de gran regocijo. Dicho santuario se consideraba que era el más antiguo del Ática y, según la tradición, como se ve en Ifigenia en Táuride, de Eurípides, la desdichada joven debió de ser enterrada en Brauron, donde se situaba la tumba de Ifigenia, en una cueva abierta en una de las rocas que existian en torno al santuario.

Afrodita, en su versión de diosa marina, surgida de la espuma del mar, acostumbraba a cabalgar sobre cisnes o delfines y se le solían ofrecer palomas y conchas marinas (figura 15). Hades, como Señor de las tinieblas, conducía un carro tirado por cuatro briosos caballos negros, en el cual había raptado a Proserpina. 


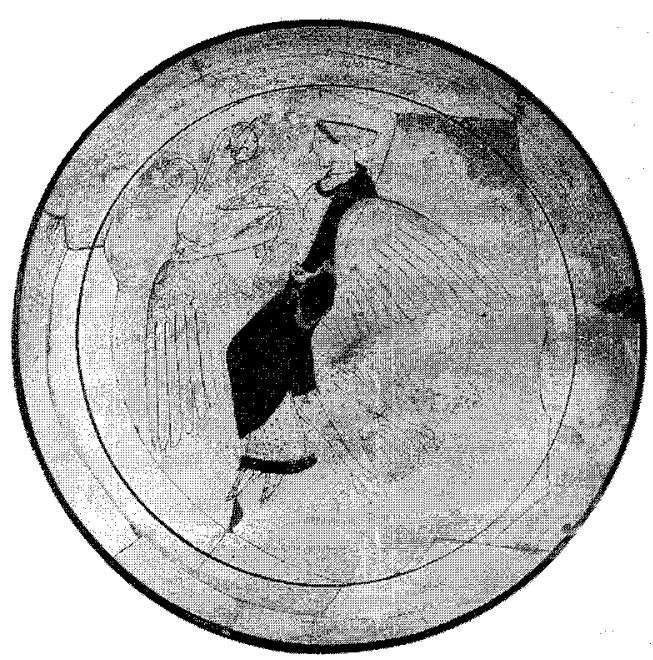

Figura 15. Kylix ático procedente de Camiro (Rodas) con la representación de Afrodita sobre una oca (hacia 480 a.C.). British Museum. Londres.

Los toros, caballos, corzas y jabalíes (figura 16) fueron animales de la fauna real, protagonistas de numerosos mitos, en muchos de los cuales jugaron un papel importante. Aún teniendo como modelo las fieras reales, todas ellas gozaban de una características especiales que las convertían en criaturas singulares y casi mágicas.

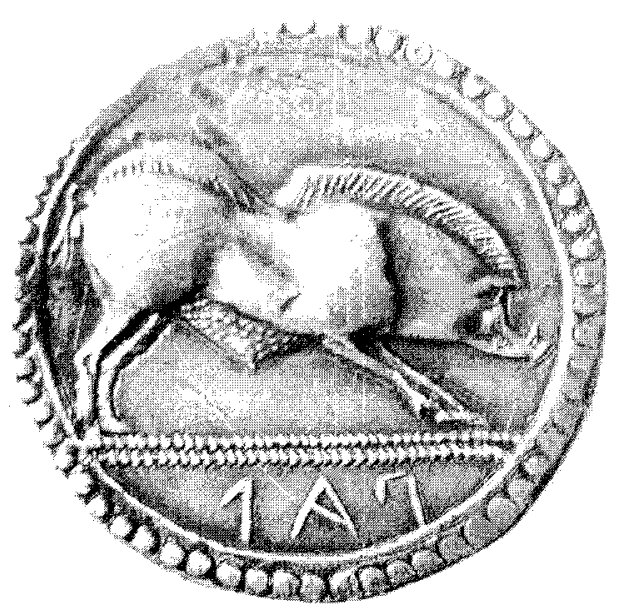

Figura 16. Moneda griega de Palinuros (hacia el 530-510 a.C.) con la representación de un jabali. 


\section{ANIMALES FANTÁSTICOS Y MONSTRUOSOS}

Como ya se ha dicho, la ingente cantidad de monstruos y seres fantásticos que poblaron las hazañas de los dioses, semidioses y héroes griegos no pueden considerarse como animales venerandos, sino símbolos de las fuerzas desatadas de la naturaleza que, en cada caso, asolaban regiones y ponían asechanzas a los hombres, por lo que éstos tenían que luchar con ellas hasta su exterminio.

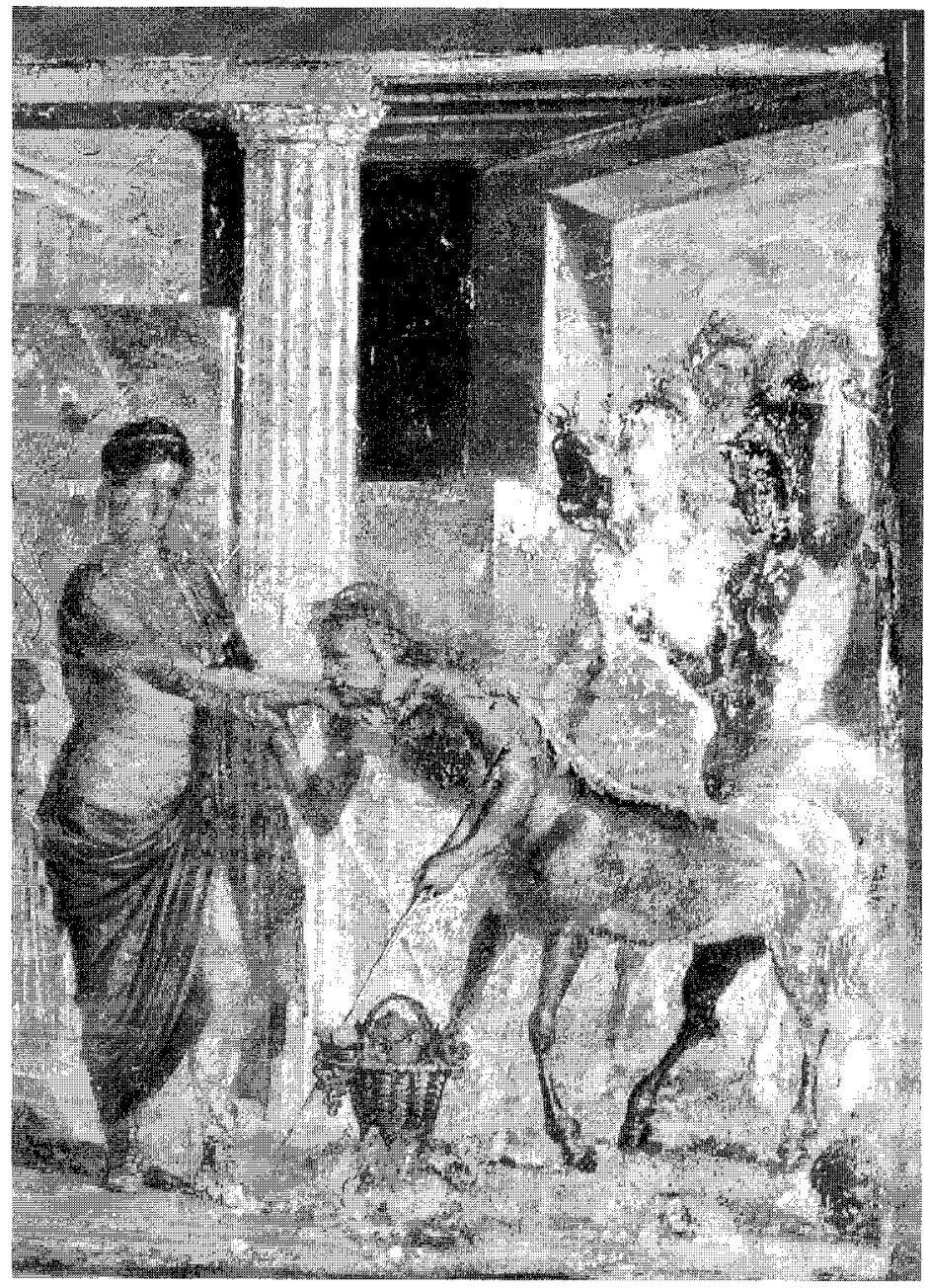

Figura 17. Pintura pompeyana con la representación de los centauros en la corte de Pirotoo (siglo i d.C.). Museo Nacional de Nápoles. 
También hay que recordar que los dioses poderosos, tuvieron su $\theta i \alpha-$

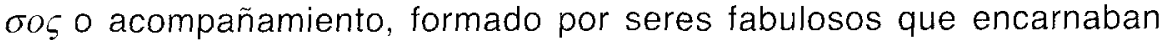
los aspectos más incomprensibles o los más cercanos al hombre. Tal fue el caso de Posidón, con su cortejo de nereidas, tritones, Escila, Equidna, etc.; o el de Dioniso, que como dios vegetal aparecía rodeado de un cortejo de entes de carácter naturalista y favorecedores de la procreación: náyades (ninfas de las aguas), hamadriades (de los árboles), oréadas (de las montañas), nepeas (de los desfiladeros y valles); faunos y sátiros (representación de la sexualidad incontrolada); centauros (seres en los que los instintos prevalecen sobre la razón); y machos cabríos, que eran los animales que se sacrificaban en sus fiestas y que, con el tiempo, pasaron a convertirse en animales representativos del mismo demonio. En consecuencia, llegaron a ser imprescindibles en las ceremonias satánicas, tal fue la fuerza que en la antigüedad tuvieron las bacanales romanas (figuras 17 y 18) que, aunque prohibidas por el senado romano en el año 186 a.C., en los medios rurales tuvieron una larga pervivencia.

La serpiente Pitón, señora multisecular de Delfos, siempre con carácter oracular, fue un último estadío del culto ofiolátrico de épocas remotas. El caballo alado, Pegaso, se convirtió en el hermoso corcel montado por Be-

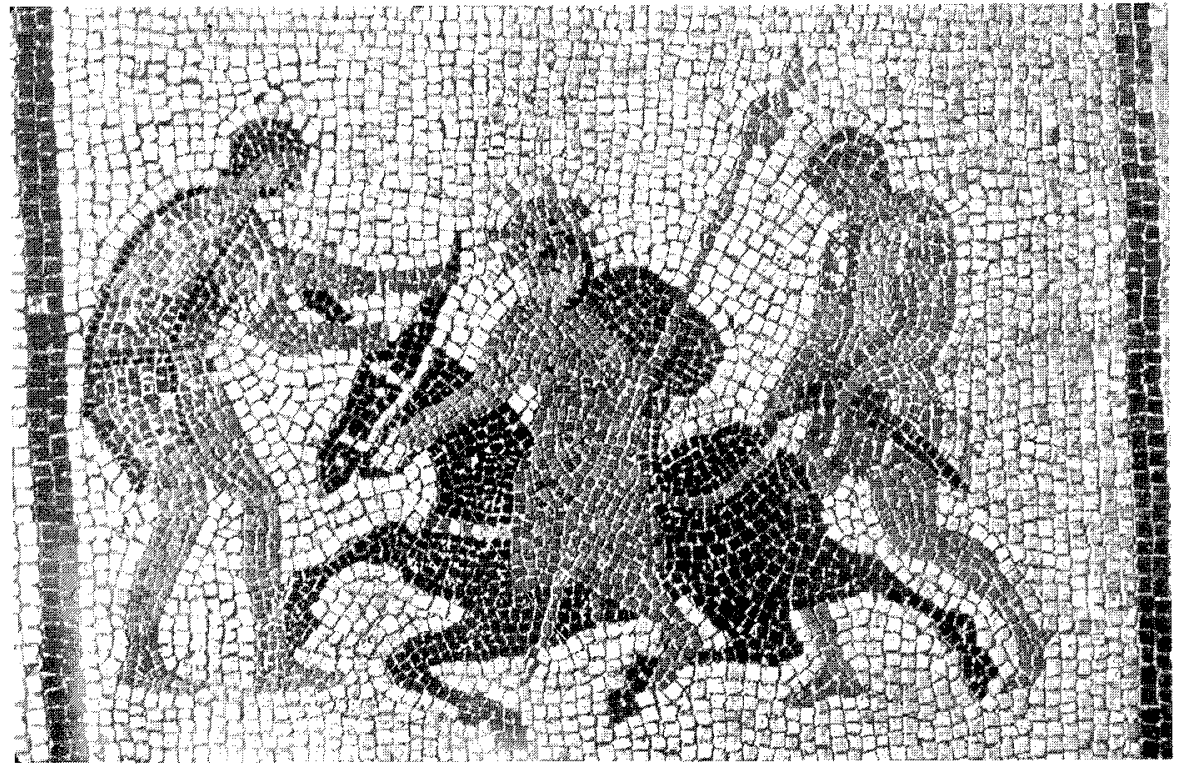

Figura 18. Mosaico pompeyano procedente de la Casa de Paquius Proculus, con la representación de un asno y un sileno (siglo / d.C.). Museo Nacional de Nápoles. 
lerofonte (figura 19), y buena parte de otros viejos monstruos, entre ellos los del lejano occidente, aparecieron en las hazañas de Hércules: la hidra de Lerna, el Can Cerbero, el monstruoso perro Ortro de Gerión y, más tarde, en el ciclo de Teseo.
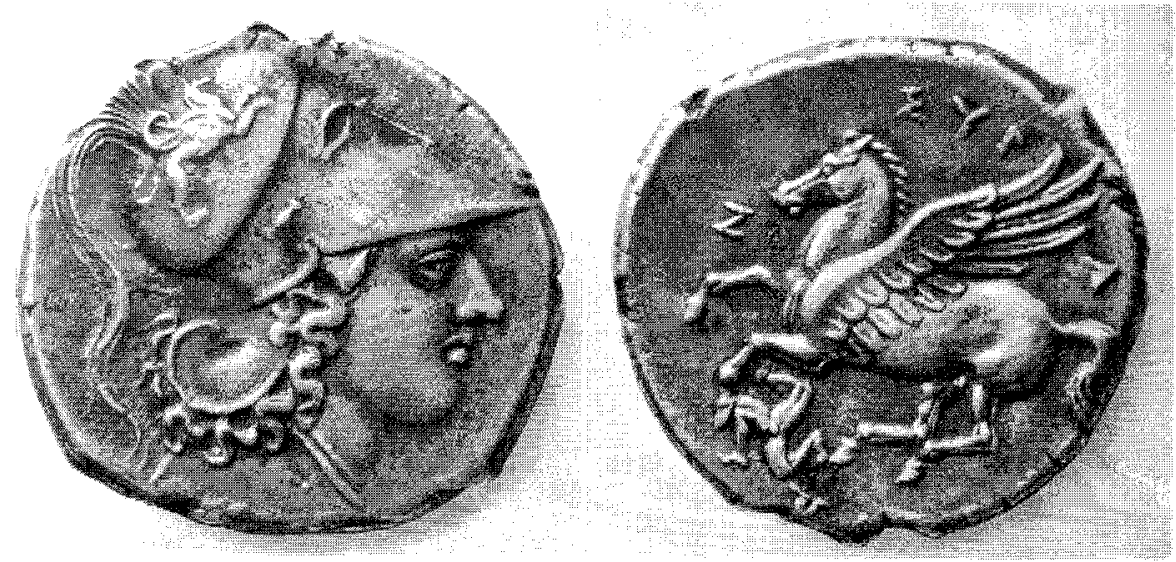

Figura 19. Moneda griega con la representación de Atenea y Pegaso (310-304 a.C.).

Mujeres pájaros fueron las Sirenas (figura 20), las Arpías y las Ceres, y todas ellas con fama de causar desgracias a los hombres, al igual que las Gorgonas de cabellos de serpiente, dientes de jabalí, manos de bronce, alas de oro y mirada petrificadora. De las tres hermanas, Esteno, Euríale y Medusa, sólo la última era mortal, por esta razón Perseo pudo cortar su cabeza utilizando las sandalias aladas que le diera Hermes y, como espejo, para evitar la mirada de su adversaria, su pulimentado escudo. Del cercenado cuello del monstruo nacieron los dos seres que en ella había engendrado Posidón: Pegaso, el caballo alado y Crisaor, el hombre de la espada de oro.

Es obvio que resulta imposible, en unas breves líneas, esbozar ni tan siquiera los perfiles míticos de todos los seres fantásticos que poblaron los mitos griegos, precursores de los que reaparecerán en narraciones posteriores, tales como las de Simbad el marino y en las novelas de aventuras bizantinas y medievales. No obstante, lo importante es constatar que en la cultura griega no cabe hablar de zoolatría, strictu sensu, como decíamos al principio, sino de una imaginación creadora y racionalista, fabuladora de historias, de la que somos sus afortunados herederos. 


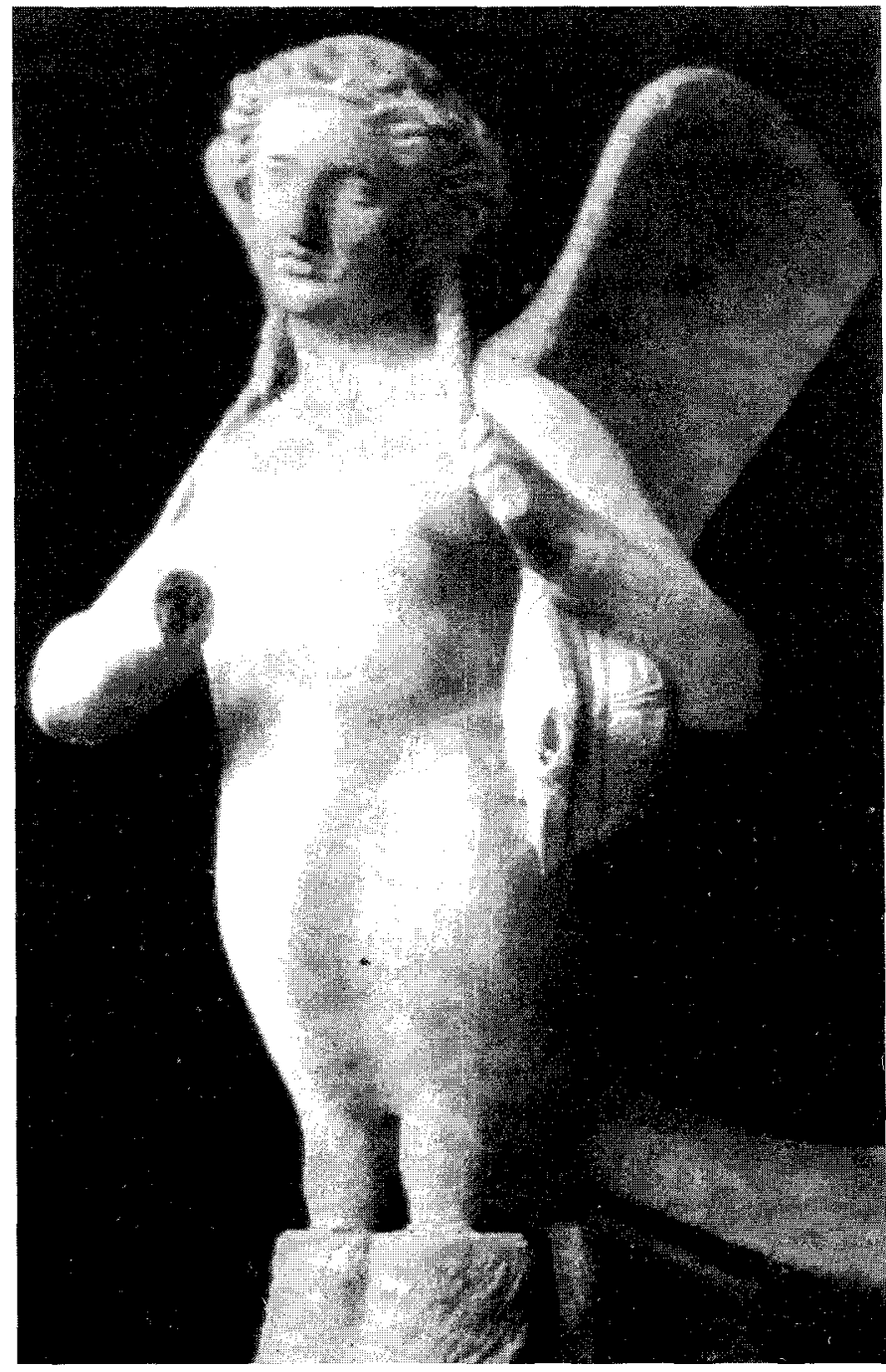

Figura 20. Estatua de Sirena procedente del cementerio del Dipylon en Atenas (siglo $v$ a.C.). Museo Nacional de Atenas.

De forma inexplicable, sin embargo, enire nosotros se mantiene ese culto al toro, de raíces neolíticas, prehelénicas, en virtud del cual, aún se llenan nuestros cosos taurinos de un público fervoroso, y nuestros toreros se visten de luces. Y con el astado, el caballo de casta compone un binomio mágico, de singular belleza. 
En otro orden de cosas, asociado a las tierras profundas de rivestra geografía, aún cabría hablar del lobo y también del águila real, animales que, en lejanos tiempos, fueron el motivo ornamental preferente de un gran número de nuestras cerámicas ibéricas. Emblemas decorativos de trazos inconfundibles.

\section{BIBLIOGRAFÍA}

Gallardo López, M.D., 1995: Manual de Mitología Clásica, Madrid. García Gual, C., 1992: Introducción a la Mitología Griega, Madrid. Grant, M., 1963: Myths of the Greeks and Romans, Londres.

Graves, R., 1985: Los mitos griegos, Madrid.

GuzMÁN, A., 1995: Dioses y Héroes de la Mitología Griega, Madrid

Nilson, M.J., 1969: Historia de la religiosidad griega, Trad. M. Sánchez Ruipérez, Madrid

PINARD DE LA Boullaye, H., 1964: Estudio comparado de las religiones, Barcelona.

SCHMIDT, W., 1941: Manual de historia comparada de las religiones, Madrid.

Tachi Venturi, P., Castellani, G., 1971: Storia delle religioni, 5 vols., Turin. 